\title{
A Fuzzy Logic Based Power Management System for a Hybrid Microgrid
}

\author{
Md. Shamsul Arifin \\ Department of Electrical and Computer Engineering, Memorial University of Newfoundland, St. John's, NL, Canada
}

\begin{tabular}{|c|c|}
\hline Article Info & ABSTRACT \\
\hline Article history: & \multirow{9}{*}{$\begin{array}{l}\text { A fuzzy logic-based power management system for a hybrid microgrid is } \\
\text { designed in this paper. This designed system is capable to manage the } \\
\text { generations considering the load conditions. Consequently, a balance is } \\
\text { maintained between generations and load. Furthermore, the system is capable } \\
\text { to monitor and manage the storage system charging and discharging as well as } \\
\text { to support the external load by sharing power as per considering the situation. } \\
\text { Moreover, to make this system more efficient it is such designed that, the } \\
\text { storage system will not take any energy from the conventional generation units } \\
\text { of the microgrid. Additionally, it is also ensured that, no power will be } \\
\text { delivered to the external load utilizing storage or generator. The "Fuzzy Logic } \\
\text { Designer" toolbox of MATLAB is used to observe the relationship between } \\
\text { the input and output variables, after establishing the fuzzy sets and rules. } \\
\text { Furthermore, transferring the fuzzy data sets and rules to MATLAB Simulink } \\
\text { and performing different case studies, the effectiveness of the designed system } \\
\text { is verified numerically. }\end{array}$} \\
\hline Received Jul 24, 2020 & \\
\hline Revised May 27, 2021 & \\
\hline Accepted Jun 7, 2021 & \\
\hline Keywords: & \\
\hline Fuzzy logic & \\
\hline Power management system & \\
\hline Hybrid microgrid & \\
\hline Renewable energy sources & \\
\hline
\end{tabular}

Copyright (C) 2019 Institute of Advanced Engineering and Science. All rights reserved.

\section{Corresponding Author:}

Md. Shamsul Arifin

Department of Electrical and Computer Engineering,

Memorial University of Newfoundland,

St. John's, NL, Canada.

Email: msarifin@mun.ca

\section{INTRODUCTION}

The modern power system is entirely different from the classical one. One of the main differences includes the penetration of renewable energy sources (RESs). Among a number of RESs, the solar PV and wind turbine-based systems are mostly utilized in hybrid systems. However, the penetration of the RES is increasing day by day. Furthermore, the types of loads and their characteristics are also different from conventional one as most of the modern electrical loads have incorporated electronic components. Additionally, the modern power system incorporates embedded and distributed generations. Considering all this matters, the idea of microgrid is becoming widespread day by day. However, the response of microgrid is quite different from the conventional power grid. That is why the management of energy in a microgrid is a challenge for the researchers and engineers [1-11]. Most of the problems arise in the microgrid due to unpredictable behaviour of source and load. As a result, microgrid management and control has become a prominent research field within the few decades [1-15].

The classical power system includes conventional generation units and classical loads. Most of the industrial and non-industrial loads are electrical components and show linear characteristics. However, in the classical system, the key advantage is that, the generations are not distributed and contributed in the system from some specific point of power stations. Consequently, it is easier to control and manage the whole system efficiently. Early control concept incorporates droop control i.e. real power-frequency (P-f) and reactive powervoltage $(\mathrm{Q}-\mathrm{V})$ control. Both the P-f and Q-V relationships are linear in nature [15-17].

On the contrary in the modern system, a large number of distributed RESs are penetrating. These RESs incorporate some problems in the system. The RESs is dependent on weather and unpredictable in nature. Therefore, it is indeed a challenge to balance the power in the grid at real time. Moreover, most of the RESs 
has very low mechanical inertia due to having no rotating parts. As a result, the transient stability, frequency and voltage regulation are affected [16-18]. Additionally, the load characteristics are also changed with the advancement of power electronics. Presently, most of the industrial loads introduce power electronics based rectifiers, inverters and converters which causes harmonics problem, poor voltage regulation etc [19-23]. Thereby, it is essential for the researchers to introduce recent techniques in the field of microgrid system and electrical energy management.

A microgrid is usually a small power grid introducing generations and loads in a limited scale. However, there are some significant technical differences between microgrid and power grid. A typical microgrid may incorporates renewable energy sources (RES), fuel cells, conventional energy sources (CES), storage system, loads etc. The microgrid may have the capacity to run independently or it may be a portion of large grid. It may also have an interconnection with other microgrid or power grid [2-4, 9, 10, 24]. A microgrid operation can be classified in two modes like stand-alone mode (or island mode) and interconnected mode. In stand-alone mode the grid is independent to generate and consume the power. However, it is also independently responsible for balancing its power, frequency regulation, voltage regulation etc. On the other hand, in interconnected mode the microgrid is interconnected with any other microgrid or a large power grid. In that case the power generation and balancing are influenced by the other connected microgrid or system.

Like a power grid, it is important to maintain a balance between the generation and consumption in a microgrid. Otherwise, the frequency and the voltage of the system will not remain within the desired range. In classical system, the balance was obtained by controlling the generation with load variation. Consequently, the voltage and frequency were kept in a desired range. However, due to the presence of distributed RES in a microgrid it is not effective to incorporate classical control scheme. As a result, frequency regulation and voltage fluctuation are common problems for the microgrid [1,3-5, 16, 17]. For these reasons it is essential to develop effective power management schemes for microgrid. However, designing an effective power management scheme also has a great importance in modern power engineering sector.

The microgrid related research has become prominent over the decades with the RESs being popular. A microgrid containing RESs, usually have the problem of frequency and voltage fluctuation. Additionally, the microgrid has low mechanical inertia due to having high RESs penetration $[2,10,11,18]$. It results more frequency fluctuation even if a small disturbance occurs. Moreover, power balancing and management is a vital issue as most of the RESs are dependent on weather and are not always predictable. The issue becomes severe with the fluctuation of loads connected to the microgrid. That is why, most of the time unbalance power occurs in microgrid. So, research related to frequency regulation and providing virtual inertia to the microgrid is becoming popular. Significant amount of research have been done addressing these problems [1-15, 18, 25]. Another vital research field related to microgrid is the stability issues. This field incorporates the oscillatory behaviour of the frequency and voltage, due to some sudden change of load or generation [15-17]. In total, the microgrid control and management concept incorporate the field of frequency and voltage regulation and transient and other stability either collectively or individually. However, it also incorporates the issue of power balancing and sharing.

A number of control schemes are developed to control the micro grid [1-9, 11, 14]. Some researchers also incorporates the artificial intelligence (AI) as the primary tool or the secondary one to control and manage microgrid [12-15, 18, 25-30]. Among the application of all AI schemes, fuzzy logic based control is most popular especially for the power system engineers and industrial electronics application sector. Fuzzy logic is a simple and helpful tool instead of classical Boolean logic in so many applications of science and engineering. Fuzzy logic-based control scheme is popular to the researchers for having several advantages like reliability, accuracy, simplicity, as well as easy to implement. Furthermore, It is used as a reliable tool for power system control, motor speed control, aerospace control, power converter control, Maximum Power Point Tracking (MPPT) algorithm of solar photovoltaic (PV) system etc [10-15, 25, 28, 30-35]. However, some other recent significant research strategies regarding microgrid control include multi-agent-based control, fuzzy logic control, particle swarm optimization (PSO) techniques, modified hill climbing methods etc [2, 4, 11-15, 25, 31, 32].

In this paper, a fuzzy logic-based control and management scheme for a hybrid microgrid is designed and verified through simulation and case studies. The major control objectives include as follows,

- To control the total power generation in microgrid considering the load variation.

- To manage the power required for storage system considering both the load variation and charge storage system.

- To manage the power delivered to another grid considering both the load variation and charge storage system.

- To prevent the storage system from drawing power from diesel generators.

- To prevent the generators and the storage system to supply power in the case of external load requirement. 
The paper is organized as follows. An overview of fuzzy logic-based system is given in section 2. Furthermore, the structure and working principle of the hybrid microgrid is illustrated in section 3 . In section 4 control architecture of the proposed fuzzy controller is discussed. The results and several case studies are discussed in section 5 to verify the effectiveness of the proposed scheme. At last a conclusion is drawn in section 6 .

\section{AN OVERVIEW OF FUZZY LOGIC-BASED SYSTEM}

Fuzzy logic can be defined as a multi-leveled logic system, where the range of level lies between 0 to 1. Fuzzy system is different from Boolean system as in the Boolean system there are two discrete levels either 0 or 1 . On the contrary instead of totally "True" or "False" concept, there are options to incorporate "partial True" or "partial False" concept in fuzzy logic-based system. Consequently, it is a powerful mathematical tool for data manipulation and forecasting [36, 37]. Figure 1 represents a typical architecture of a fuzzy based system. The inputs are converted to fuzzy set with the help of fuzzification, which is a procedure to convert the numerical input to a degree of membership which has a range of $[0,1]$. The Fuzzy system evaluates outputs based on input fuzzy sets and the given rules. The outputs are further converted to numerical values using defuzzification. Usually the fuzzy logic system is operated using the following two equations:

$$
\begin{aligned}
& \phi \mathrm{C}[\mu \mathrm{A}(\mathrm{x}) * \mu \mathrm{B}(\mathrm{y})]=\mu \mathrm{A}(\mathrm{x}) \cap \mu \mathrm{B}(\mathrm{y}) \\
& x=\frac{\int x * \mu f(x) d x}{\int \mu(x) d x}
\end{aligned}
$$

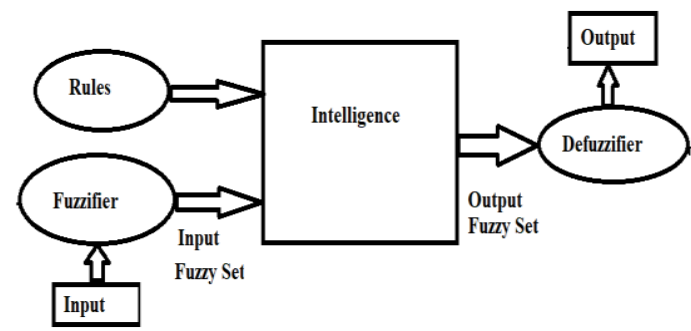

Figure 1. A typical fuzzy logic control-based system.

\section{STRUCTURE AND WORKING PRINCIPLE OF THE CONSIDERED HYBRID MICROGRID}

The structure of the considered hybrid microgrid is illustrated in Figure 2. This microgrid has both AC and DC buses. The solar PV is considered as RESs for this microgrid. For simplicity, two identical solar PV units, having total capacity of $4.0 \mathrm{KW}$ are considered here for operation. Similarly, there is a storage system also having capacity of $2.0 \mathrm{KW}$. Additionally, the system contains two diesel generators having capacity of 2.0 $\mathrm{KW}$ each. The loads are connected to the AC bus and thereby it is assumed that all the considered consumptions are from AC bus. There is an inverter connected between AC and DC bus. This microgrid has its total capacity of $10 \mathrm{KW}$.

In this proposed hybrid microgrid the power balancing and management is performed using the fuzzy logic controller. The microgrid have solar PV and diesel generations as well as a storage system. When the load is low the RESs are utilized to meet the power demand. Moreover, When the load is high the storage and diesel generators support the demand gradually. However, there are also some restrictions for storage not to take power from the diesel generators and no power will be transmitted to external load from storage as well as from generators.

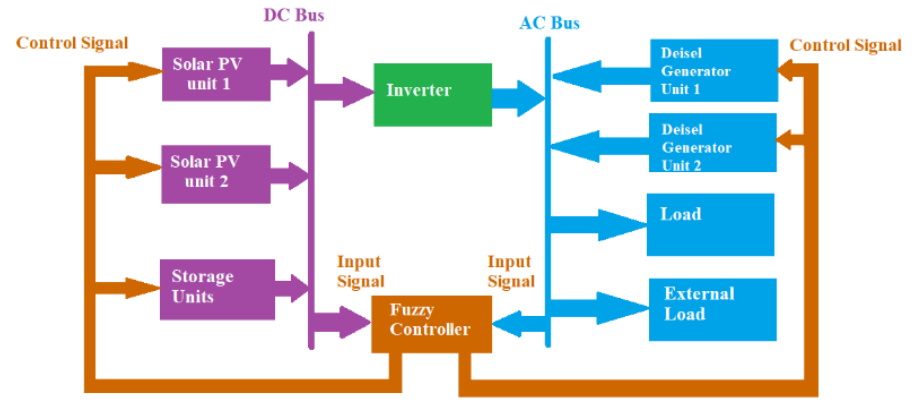

Figure 2. The structure of the proposed system.

\section{CONTROL ARCHITECTURE OF THE PROPOSED FUZZY CONTROLLER}




\subsection{Input and Output Parameters}

The microgrid usually operates at a frequency of $50 \mathrm{~Hz}$ at a nominal load of $5 \mathrm{KW}$. The change of frequency $(\Delta f)$ is considered as one of two input variables for managing the system. The frequency change represents the load changing condition in the microgrid. The State Of Charge (SOC) of storage unit is considered as another input, which represents the status of stored energy in the system. For designing the input membership function the inputs are divided into several steps. Table 1 and 2 shows the details numerical range of two input membership functions.

On the other hand, three quantities will be considered as output variables. They are, power generation in microgrid (P_G), the power required for storage system (P_S) and the power delivered to external grid (P_D). The output variables are also divided into several steps for forming membership functions. The output variable "power generation $\left(\mathrm{P}_{-} \mathrm{G}\right)$ " is divided into several schemes for better understanding. Table 3 to 5 shows the details numerical range of three input membership functions.

Table 1. Steps of membership functions for input variable "Change of frequency $(\Delta \mathrm{f})$ "

\begin{tabular}{cc}
\hline Steps & Membership Range (Hz.) \\
\hline Very Negative (V_Neg) & -1 to -0.5 \\
Negative (Neg) & -1 to 0 \\
Zero & -0.5 to 0.5 \\
Positive (Pos) & 0 to 1 \\
Very Positive (V_Pos) & 0.5 to 1 \\
\hline
\end{tabular}

Table 2. Steps of membership functions for input variable "State Of Charge (SOC)"

\begin{tabular}{cc}
\hline Steps & Membership Range (in \%) \\
\hline Very Low (V.Low) & $25-50$ \\
Low & $25-75$ \\
Medium (Mid) & $50-100$ \\
Full & $75-100$ \\
\hline
\end{tabular}

Table 3. Steps of membership functions for output variable "Power Generation (P_G)"

\begin{tabular}{ccc}
\hline Schemes & Significance & $\begin{array}{c}\text { Membership } \\
\text { Range (KW) }\end{array}$ \\
\hline Scheme1 (S1) & One unit of Solar PV supports & $0-2.5$ \\
Scheme2 (S2) & Both units of Solar PV support & $0-5.0$ \\
Scheme3 (S3) & Both units of Solar PV and Storage system support & $2.5-7.5$ \\
Scheme4 (S4) & Both units of Solar PV, Storage system and One unit of diesel generator support & $5.0-10.0$ \\
Scheme5 (S5) & Both units of Solar PV, Storage system and both units of diesel generator support & $7.5-10.0$ \\
\hline
\end{tabular}

Table 4. Steps of membership functions for output variable "Power for Storage (P_S)"

\begin{tabular}{cc}
\hline Steps & Membership Range (KW) \\
\hline Zero & $0-0.05$ \\
Low & $0-1.0$ \\
Medium (Mid) & $0-2.0$ \\
High & $1.0-2.0$ \\
\hline
\end{tabular}

Table 5. Steps of membership functions for output variable "Power Delivered to Grid (P_D)"

\begin{tabular}{cc}
\hline Steps & Membership Range $(\mathrm{KW})$ \\
\hline Zero & $0-0.05$ \\
Low & $0-1.0$ \\
Medium (Mid) & $0-2.0$ \\
High & $1.0-2.0$ \\
\hline
\end{tabular}

\subsection{Fuzzy Rules}

The fuzzy rules are developed considering various combinations of input variable steps to design the proposed control and management scheme. The different steps of output variables are set at different input conditions. These rules are presented in Table 6 to 8. The output variables $P_{-} G$ is manipulated considering the change of frequency $(\Delta \mathrm{f})$ of microgrid, which is directly dependent to the load connected to the grid. The other variables $P_{-} S$ and $P_{-} D$ are manipulated considering both the frequency change $(\Delta f)$ and SOC of storage unit.

Table 6. Rules for controlling "Power Generation (P_G)" 


\begin{tabular}{cccccc}
\hline$\Delta \mathrm{f}$ & V_Neg & Neg & Zero & Pos & V_Pos \\
\hline P_G & S5 & S4 & S3 & S2 & S1 \\
\hline
\end{tabular}

Table 7: Rules for controlling "Power for Storage (P_S)"

\begin{tabular}{|c|c|c|c|c|c|}
\hline$\frac{\Delta \mathrm{f} \rightarrow}{\mathrm{SOC} \downarrow}$ & V_Neg & Neg & Zero & Pos & V_Pos \\
\hline V.Low & Zero & Zero & Mid & High & High \\
\hline Low & Zero & Zero & Low & Mid & High \\
\hline Full & Zero & Zero & Zero & Zero & Zero \\
\hline
\end{tabular}

Table 8: Rules for controlling "Power Delivered to Grid (P_D)"

\begin{tabular}{|c|c|c|c|c|c|}
\hline$\frac{\Delta \mathrm{f} \rightarrow}{\mathrm{SOC} \downarrow}$ & V_Neg & $\mathrm{Neg}$ & Zero & Pos & V_Pos \\
\hline Low & Zero & Zero & Zero & Mid & Mid \\
\hline Full & Zero & Zero & Zero & High & High \\
\hline
\end{tabular}

\section{RESULTS AND OBSERVATION}

\subsection{Simulation model}

For verifying the effectiveness and functionality of the proposed fuzzy system, the simulation is performed considering the fuzzy sets of input and output variables and fuzzy rules as described in section 4. The "Fuzzy Logic Designer" toolbox of MATLAB is used for simulation. Figure 3 represents the simulation model of the proposed fuzzy system. The system has two input variables ( $\Delta \mathrm{f}$ and $\mathrm{SOC}$ ) and three output variables (P_G, P_S, P_D) as discussed earlier. It also incorporates a processor unit, which can process data considering inputs and exhibits proper results. Figure 4 to 8 represents the graphical representation of membership functions of input variables $\Delta \mathrm{f}$, SOC and output variables $\mathrm{P}_{-} \mathrm{G}, \mathrm{P} S \mathrm{~S}, \mathrm{P} \_\mathrm{D}$.

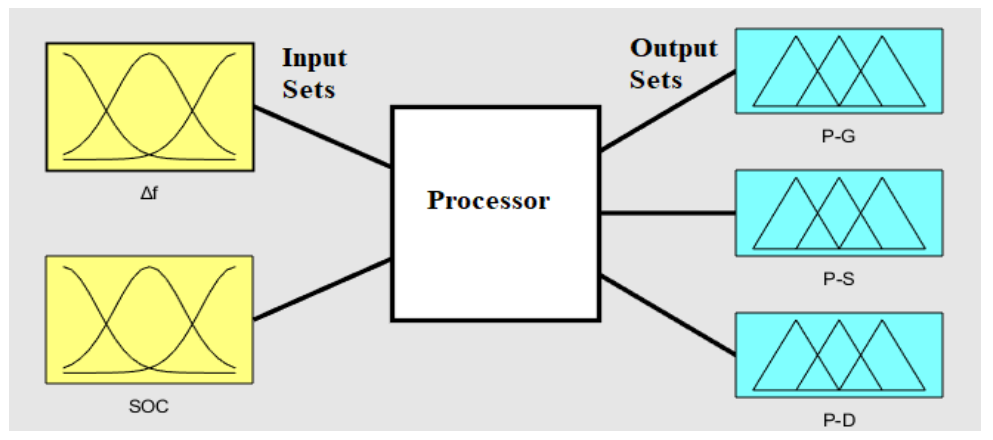

Figure 3. Model for Simulation.

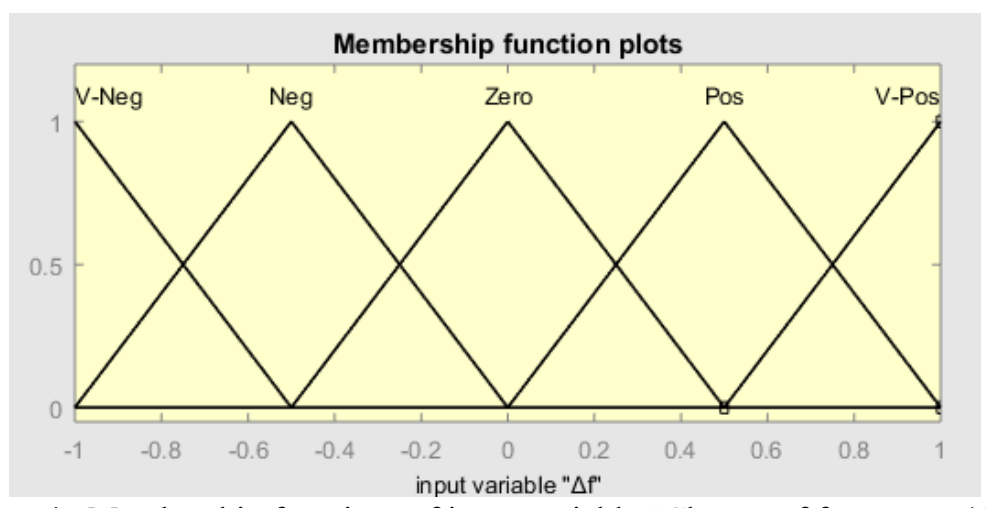

Figure 4. Membership functions of input variable "Change of frequency $(\Delta \mathrm{f})$ ". 


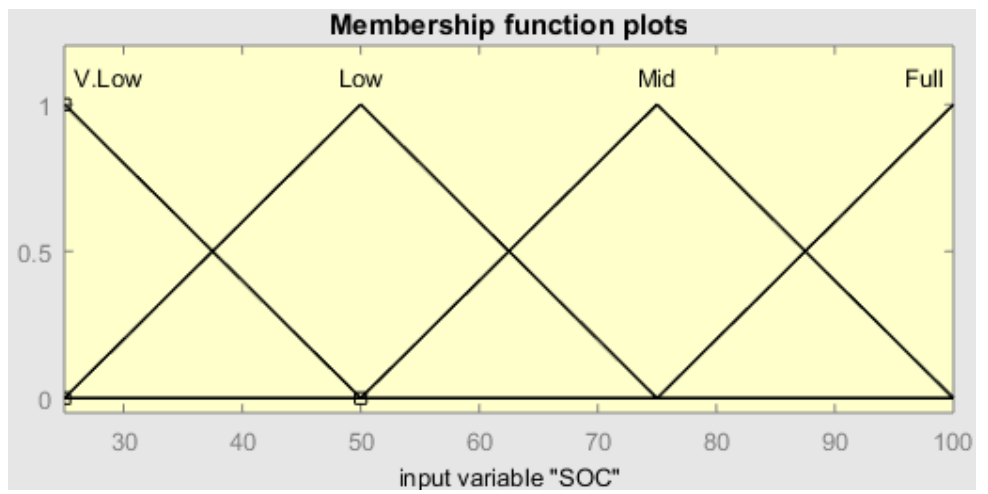

Figure 5. Membership functions of input variable "State of charge (SOC)".

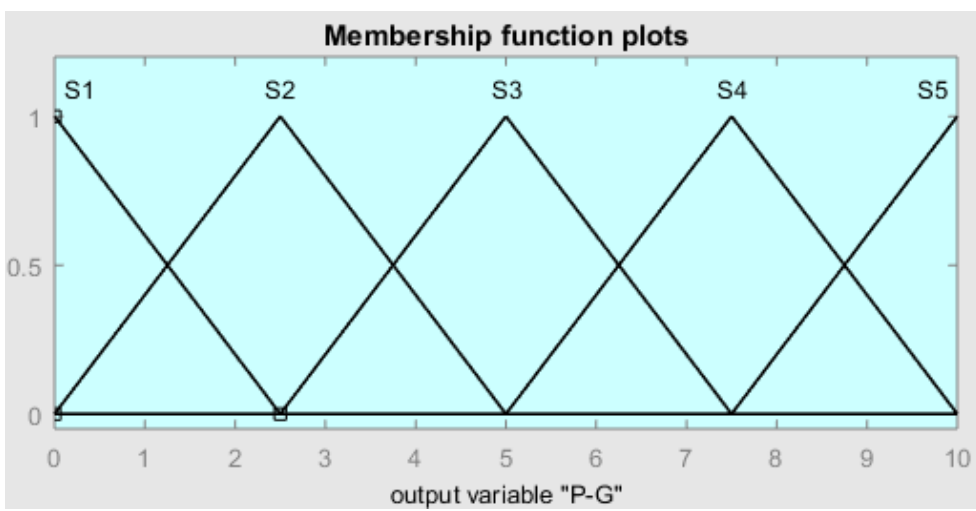

Figure 6. Membership functions of output variable "Power Generation $\left(P_{-} G\right)$ ".

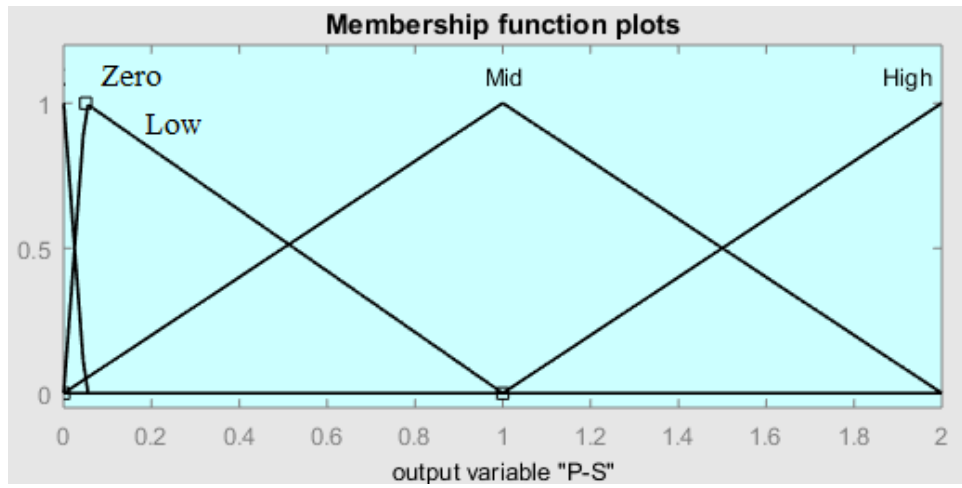

Figure 7. Membership functions of output variable "Power for Storage (P_S)".

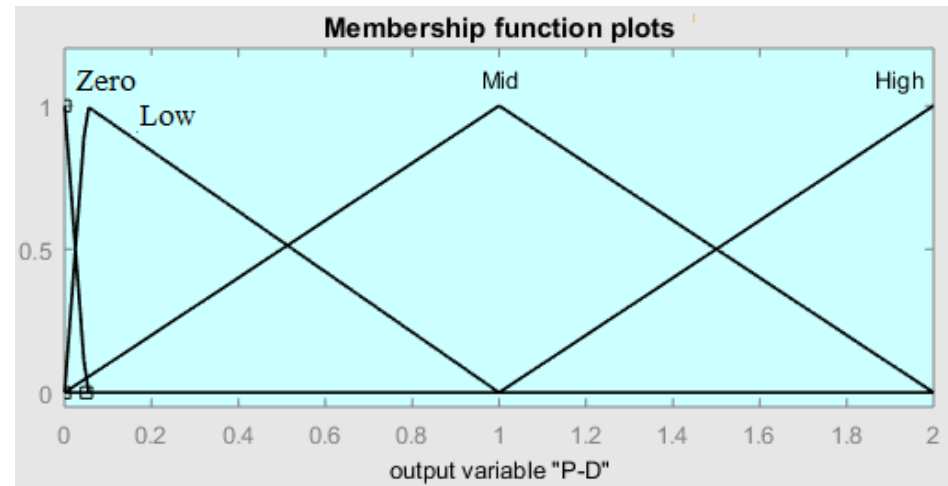

Figure 8. Membership functions of output variable "Power Delivered to Grid (P_D)".

\subsection{Results from simulation}


The results are obtained setting the fuzzy sets and rules to the "Fuzzy Logic Designer" toolbox of MATLAB. The relationship between the output variables and the input variables are presented in Figure 9 to 11. Figure 9 represents the relationship of $\mathrm{P}_{-} \mathrm{G}$ to the input variables $\Delta \mathrm{f}$ and SOC. Similarly, Figure 10 represents the dependency of $\mathrm{P} \_\mathrm{S}$ on $\Delta \mathrm{f}$ and $\mathrm{SOC}$. From this relationship it is observed that, the battery storage depends on $\Delta \mathrm{f}$ and SOC. Moreover, the storage system will not take any energy when the diesel generators are generating power.

Furthermore, the relationship among $\mathrm{P}_{-} \mathrm{D}, \Delta \mathrm{f}$ and $\mathrm{SOC}$ is presented in Figure 11. From this relationship, it is evident that, the amount of $\mathrm{P}_{-} \mathrm{D}$ is dependent on on $\Delta \mathrm{f}$ and SOC. Furthermore, no power will be delivered to the external load utilizing storage or generator.

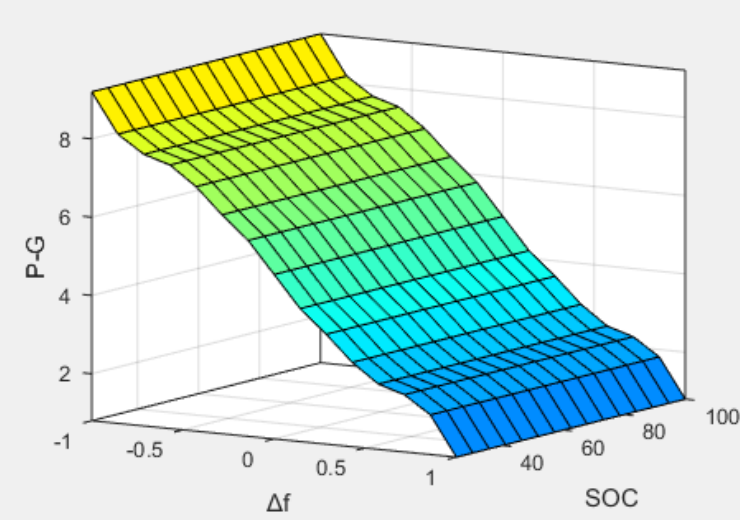

Figure 9. The relationship of $\mathrm{P}_{-} \mathrm{G}$ to the input variables ( $\Delta \mathrm{f}$ and $\left.\mathrm{SOC}\right)$.

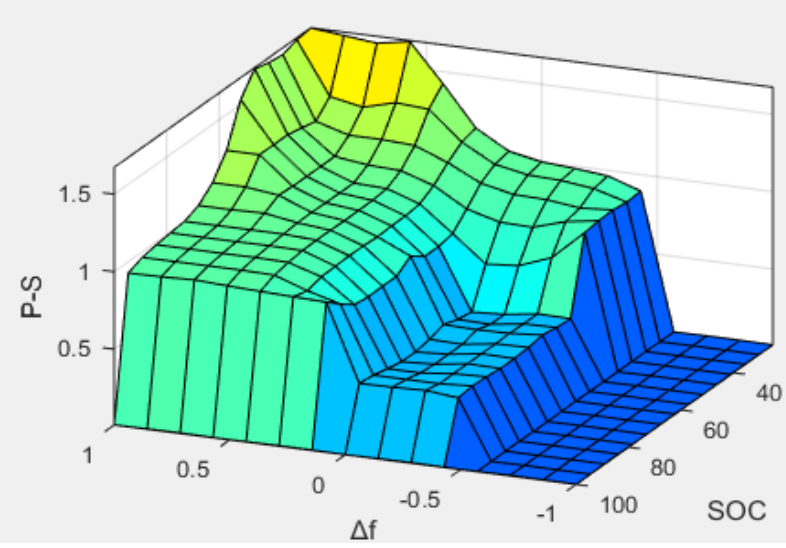

Figure 10. The relationship of $\mathrm{P} \_\mathrm{S}$ to the input variables $(\Delta \mathrm{f}$ and $\mathrm{SOC})$.

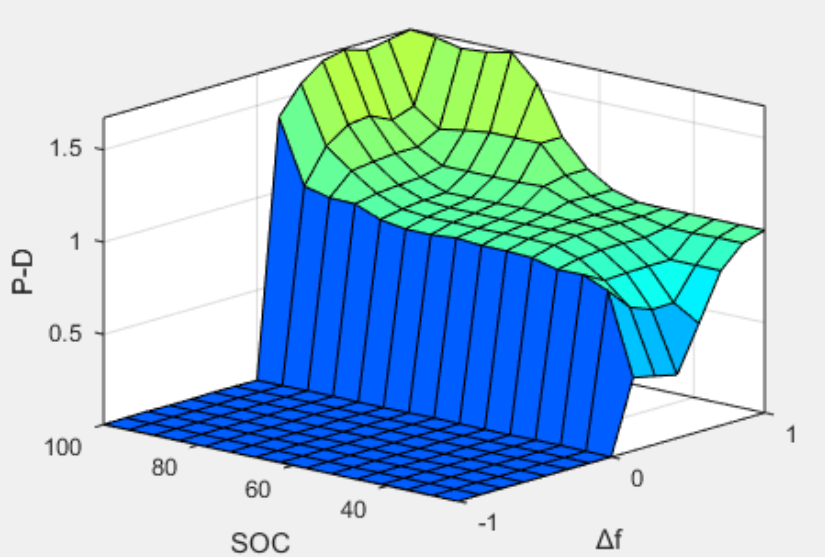

Figure 11. The relationship of $\mathrm{P}_{-} \mathrm{D}$ to the input variables ( $\Delta \mathrm{f}$ and $\mathrm{SOC}$ ). 


\subsection{Case studies and observations}

The fuzzy data sets and rules are further transferred to MATLAB Simulink for performing different case studies. These cases are selected considering the objectives as mentioned in the introduction section. These case studies prove the effectiveness of the proposed control system quantitatively. Furthermore, these cases assist to verify the achievements of control objectives. Figure 12 shows the Simulink model of the proposed system for different case studies.

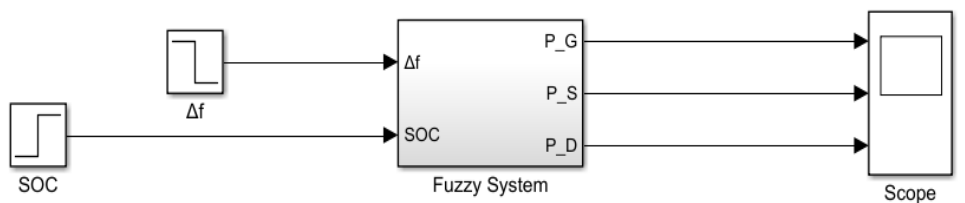

Figure 12. Simulink model of the proposed system.

Case-1: The total power generation $\left(\mathrm{P}_{-} \mathrm{G}\right)$ is adjusted considering the frequency variation $(\Delta \mathrm{f})$.

Assuming the system operating at normal load $(\Delta \mathrm{f}=0)$, the load is increased setting $\Delta \mathrm{f}=-0.5$. The response of $P_{-} G$ of this change is presented in Figure 13. From this figure it is evident that the $P \_G$ is adjusted considering $\Delta \mathrm{f}$.
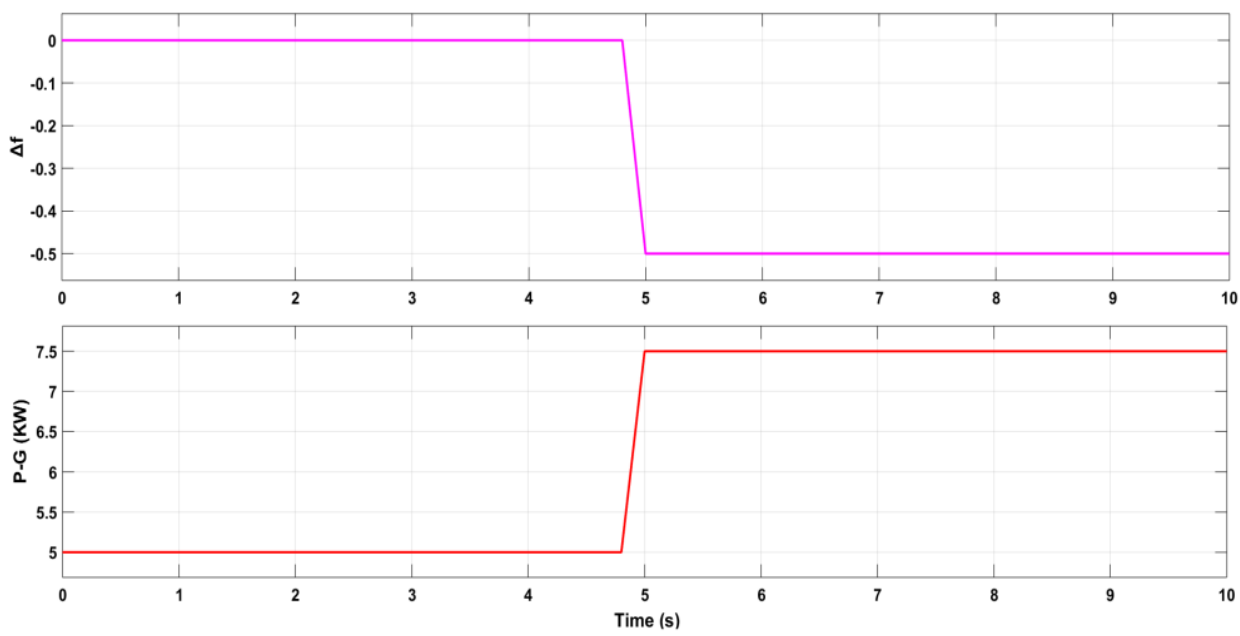

Figure 13. Verification of adjustment of $\mathrm{P} \_\mathrm{G}$ considering $\Delta \mathrm{f}$.

Case-2: Power for Storage (P_S) is controlled considering both the frequency variation $(\Delta \mathrm{f})$ and State of Charge (SOC).

In this case initially it is considered that the storage system is full $(\mathrm{SOC}=100)$ and the system is operated at normal load $(\Delta \mathrm{f}=0)$. The change in $\mathrm{P} S$ is observed numerically, by setting $\Delta \mathrm{f}=0.5$ and $\mathrm{SOC}=50$. The response of $\mathrm{P}_{-} \mathrm{S}$ is illustrated in Figure 14, which proves that $\mathrm{P} \_\mathrm{S}$ is controlled considering both $\Delta \mathrm{f}$ and SOC.

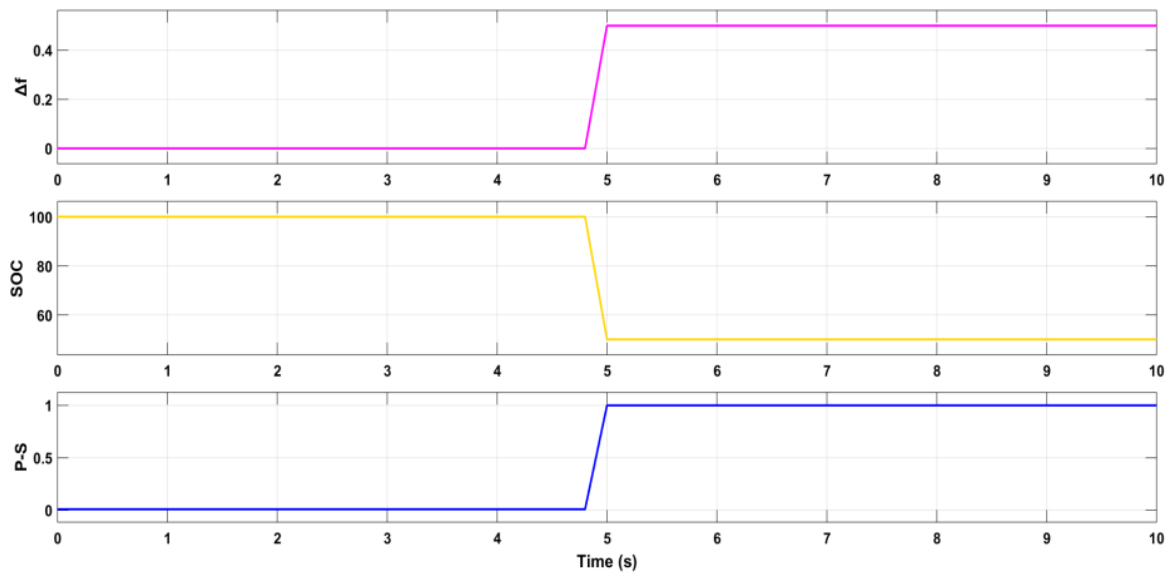

Figure 14. Verification of adjustment of $\mathrm{P} \_\mathrm{S}$ considering $\Delta \mathrm{f}$ and $\mathrm{SOC}$. 
Case-3: Power Delivered to Grid (P_D) is controlled considering both the frequency variation $(\Delta \mathrm{f})$ and State of Charge (SOC).

In this case initially it is considered that $\mathrm{SOC}=100$ and $\Delta \mathrm{f}=0$. The final value of $\Delta \mathrm{f}$ and $\mathrm{SOC}$ is adjusted to 0.5 and 75 respectively. The numerical change of $P \_D$ is illustrated in Figure 15. It verifies that $P_{-} D$ is controlled considering both $\Delta \mathrm{f}$ and SOC.

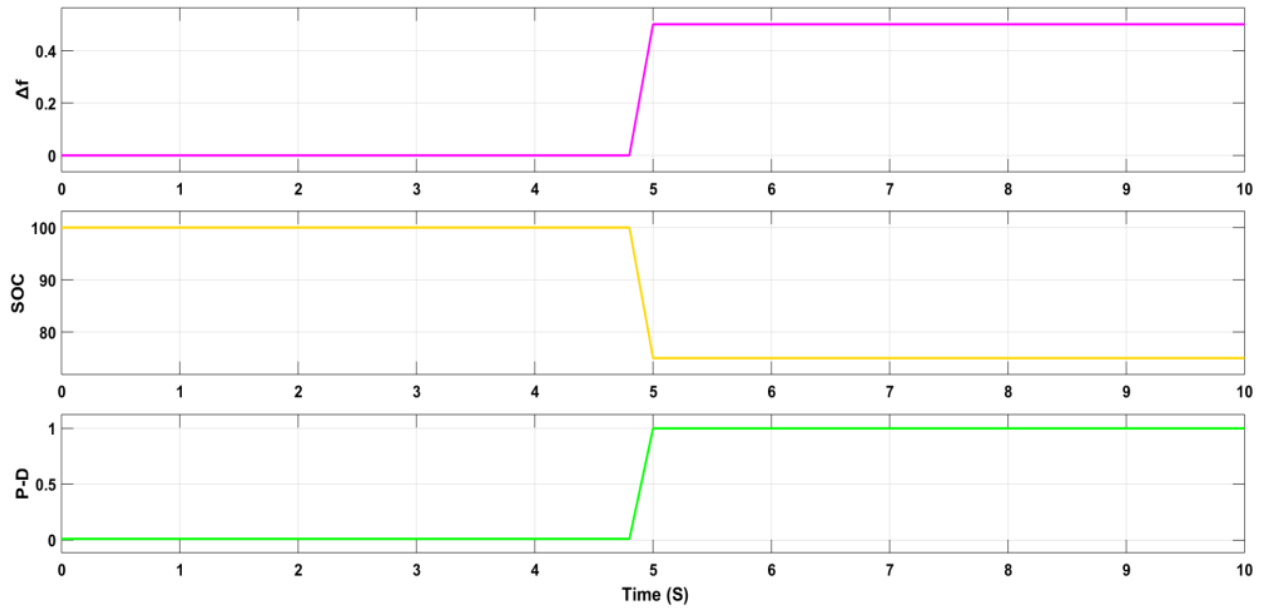

Figure 15. Verification of adjustment of $\mathrm{P}_{-} \mathrm{D}$ considering $\Delta \mathrm{f}$ and $\mathrm{SOC}$.

Case-4: The storage system cannot draw power from diesel generators.

To verify this case, it is considered that the SOC of the battery is always low. Setting a low value of $\mathrm{SOC}=50$ and change the $\Delta \mathrm{f}$ from 0.5 to -0.5 the response of $\mathrm{P} \_\mathrm{S}$ is observed. When $\Delta \mathrm{f}$ is set to -0.5 the diesel generator starts contributing to the system. As a result, although SOC is low the Power for Storage (P_S) will shift to zero as illustrated in Figure 16. It signifies no power will be drawn from diesel generators to charge the storage system.
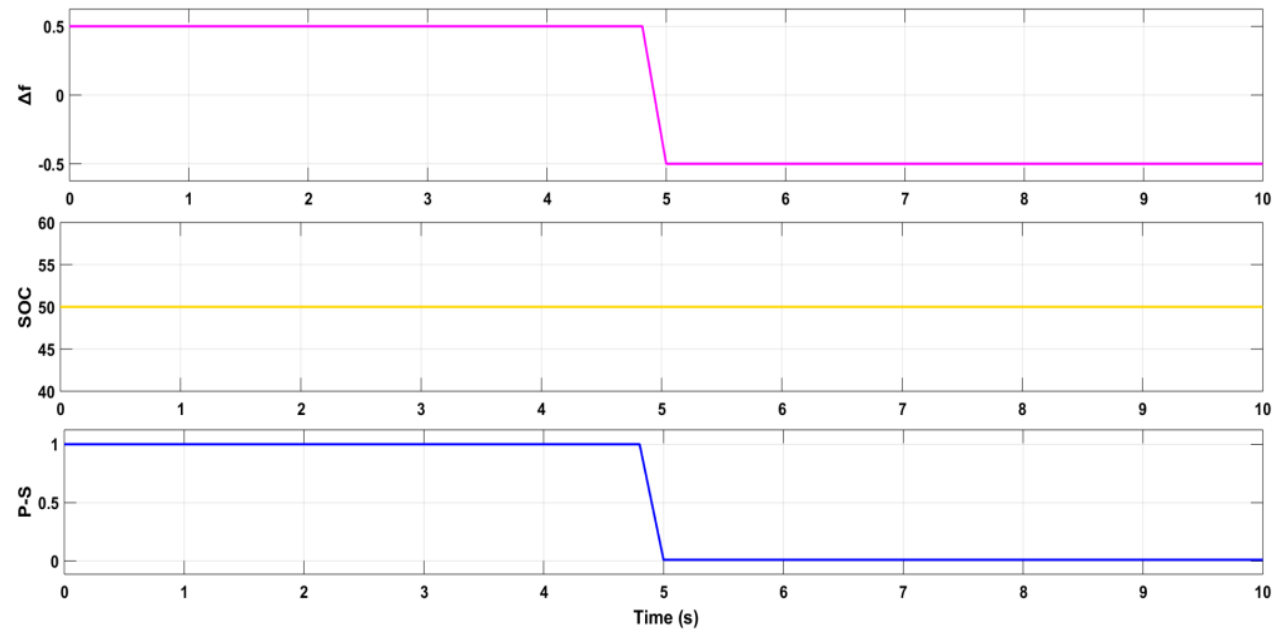

Figure 16. Verification of drawing no power from diesel generators to charge the storage system. requirement.

Case-5: The generators and the storage system cannot supply power in the case of external load

For this case, the value of $\Delta \mathrm{f}$ is changed to -0.5 from a value -0.5 . The SOC value is considered to 100. The numerical value of $P$ D is shifted to zero, when $\Delta f=-0.5$ i.e. the storage system and diesel generators contribute to the system. It signifies that no power will be flow to the external load when the generators and the storage system are working. The response of P_D is illustrated in Figure 17. It also signifies that only RESs can contribute to external load. 

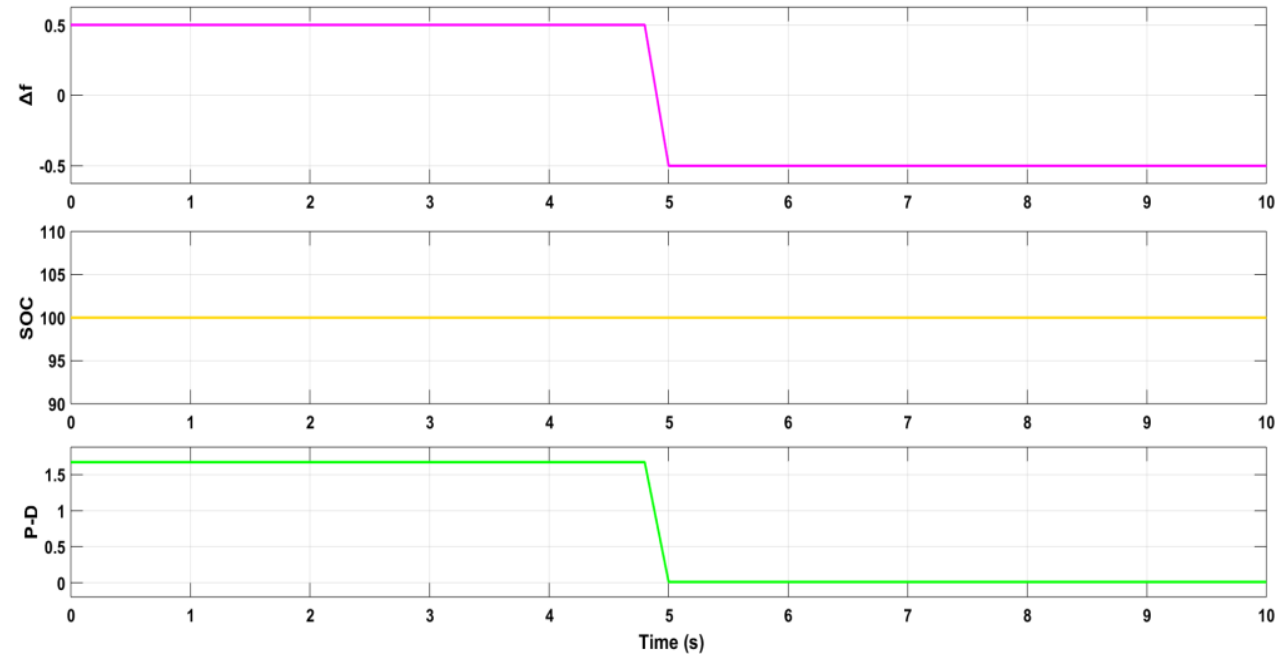

Figure 17. Verification of drawing no power from diesel generators and the storage system to external load.

\section{CONCLUSION}

In this paper, a fuzzy logic-based power management system is proposed for a hybrid microgrid. The microgrid has RES, diesel generators as well as a storage system. Actuating the change of frequency $(\Delta f)$ the amount of generation $\left(P_{-} G\right)$ is controlled. Furthermore, with the help of both change of frequency $(\Delta f)$ and SOC of the battery the power required for storage system (P_S) and the power delivered (P_D) to another grid is controlled. The functionality and the effectiveness of the system is verified using results and case studies as presented in the paper. Additionally, it is ensured that, the battery will not take power from the generation when the loads are high and diesel generators are contributing to meet the load demand. It prevents the storage to draw the power from diesel generators. Furthermore, the system is such designed that no power will be supplied to the external grid or network if the batteries or generators contributes to the generation. It also indicates that, the generators and the storage system will not contribute to the generation if there is any external load requirement. Consequently, the objectives mentioned in introduction are achieved.

The future work may incorporate the dynamic solar model for the management of the microgrid. Additionally, the transient conditions analysis of the microgrid after incorporating the proposed management scheme can also be a good research work. To implement the proposed scheme using microcontroller or embedded processor-based systems is also a vital research project.

\section{ACKNOWLEDGMENTS}

The author would like to thank the course instructor Dr. Siu O'Young for teaching the course "Advance Control Systems" in Memorial University of Newfoundland.

\section{REFERENCES}

[1] H. Nikkhajoei and R. H. Lasseter, "Microgrid Protection," in 2007 IEEE Power Engineering Society General Meeting, Jun. 2007, pp. 1-6.

[2] A. L. Dimeas and N. D. Hatziargyriou, "Operation of a multiagent system for microgrid control," IEEE Trans. Power Syst., vol. 20, no. 3, pp. 1447-1455, Aug. 2005.

[3] M. F. Roslan, M. A. Hannan, P. J. Ker, and M. N. Uddin, "Microgrid control methods toward achieving sustainable energy management," Appl. Energy, vol. 240, pp. 583-607, Apr. 2019.

[4] A. Mohammed, S. S. Refaat, S. Bayhan, and H. Abu-Rub, "AC Microgrid Control and Management Strategies: Evaluation and Review," IEEE Power Electron. Mag., vol. 6, no. 2, pp. 18-31, Jun. 2019.

[5] E. H. Trinklein, M. D. Cook, G. G. Parker, and W. W. Weaver, "Exergy optimal multi-physics aircraft microgrid control architecture," Int. J. Electr. Power Energy Syst., vol. 114, p. 105403, Jan. 2020.

[6] H. Tu, Y. Du, H. Yu, A. Dubey, S. Lukic, and G. Karsai, "Resilient Information Architecture Platform for the Smart Grid (RIAPS): A Novel Open-Source Platform for Microgrid Control,” IEEE Trans. Ind. Electron., pp. 1-1, 2019.

[7] Y. Li, K. Meng, Z. Y. Dong, and W. Zhang, "Sliding Framework for Inverter-Based Microgrid Control," IEEE Trans. Power Syst., vol. 35, no. 2, pp. 1657-1660, Mar. 2020.

[8] C. Bordons, F. Garcia-Torres, and M. A. Ridao, "Microgrid Control Issues," in Model Predictive Control of Microgrids, C. Bordons, F. Garcia-Torres, and M. A. Ridao, Eds. Cham: Springer International Publishing, 2020, pp. $1-23$.

[9] M. Gaiceanu, I. N. Arama, and I. Ghenea, "DC Microgrid Control," in Microgrid Architectures, Control and Protection Methods, N. Mahdavi Tabatabaei, E. Kabalci, and N. Bizon, Eds. Cham: Springer International Publishing, 2020, pp. 357-380. 
[10] P. Basak, A. K. Saha, S. Chowdhury, and S. P. Chowdhury, "Microgrid: Control techniques and modeling," in 2009 44th International Universities Power Engineering Conference (UPEC), Sep. 2009, pp. 1-5.

[11] D. E. Olivares et al., "Trends in Microgrid Control," IEEE Trans. Smart Grid, vol. 5, no. 4, pp. 1905-1919, Jul. 2014.

[12] F. Rodríguez, A. M. Florez-Tapia, L. Fontán, and A. Galarza, "Very short-term wind power density forecasting through artificial neural networks for microgrid control," Renew. Energy, vol. 145, pp. 1517-1527, Jan. 2020.

[13] S. Mokhtari et al., "Cloud-based microgrid control," US10606296B2, Mar. 31, 2020.

[14] A. Mohammadzadeh and E. Kayacan, "A novel fractional-order type-2 fuzzy control method for online frequency regulation in ac microgrid," Eng. Appl. Artif. Intell., vol. 90, p. 103483, Apr. 2020.

[15] J. Fattahi, H. Schriemer, B. Bacque, R. Orr, K. Hinzer, and J. E. Haysom, "High stability adaptive microgrid control method using fuzzy logic," Sustain. Cities Soc., vol. 25, pp. 57-64, Aug. 2016.

[16] Md. S. Arifin, M. M. S. Khan, A. Haque, and Nahid-Al-Masood, "Improvement of load-margin and bus voltage of Bangladesh power system with the penetration of PV based generation," in 2013 International Conference on Informatics, Electronics and Vision (ICIEV), May 2013, pp. 1-5.

[17] M. Khan, M. Arifin, A. Haque, and N. Al-Masood, "Stability analysis of power system with the penetration of photovoltaic based generation,” Int J Energy Power Eng, vol. 2, no. 2, pp. 84-89, 2013.

[18] C. Andalib-Bin-Karim, X. Liang, and H. Zhang, "Fuzzy-Secondary-Controller-Based Virtual Synchronous Generator Control Scheme for Interfacing Inverters of Renewable Distributed Generation in Microgrids," IEEE Trans. Ind. Appl., vol. 54, no. 2, pp. 1047-1061, Mar. 2018.

[19] M. S. Arifin, N. Mohammad, M. I. Khalil, and M. J. Alam, "Input switched closed-loop single phase ĈUK AC to DC converter with improved power quality," Int. J. Power Electron. Drive Syst. IJPEDS, vol. 10, no. 3, Art. no. 3, Sep. 2019.

[20] Md. S. Arifin and M. J. Alam, "Input switched high performance single phase single switch Ćuk AC-DC converter," in 2015 International Conference on Advances in Electrical Engineering (ICAEE), Dec. 2015, pp. 226-229.

[21] M. M. S. Khan et al., "Input switched high performance three phase Buck-Boost controlled rectifier," in 2013 IEEE International Conference on Industrial Technology (ICIT), Feb. 2013, pp. 557-562.

[22] M. M. S. Khan, Md. S. Arifin, Md. R. T. Hossain, Md. A. Kabir, A. H. Abedin, and M. A. Choudhury, "Input switched single phase buck and buck-boost AC-DC converter with improved power quality," in 2012 7th International Conference on Electrical and Computer Engineering, Dec. 2012, pp. 189-192.

[23] Md. S. Arifin and M. J. Alam, "Input switched single phase SEPIC controlled rectifier with improved performances," in 2016 9th International Conference on Electrical and Computer Engineering (ICECE), Dec. 2016, pp. 38-41.

[24] "Microgrid," Wikipedia. Jul. 13, 2020, Accessed: Jul. 16, 2020. [Online]. Available: https://en.wikipedia.org/w/index.php?title=Microgrid\&oldid=967454504.

[25] N. Mohammad, K. Debnath, M. Rahman, and Md. S. Arifin, "Optimal Power Delivery from Hybrid Micro-grid to Provide Frequency Regulation | Bentham Science," Recent Adv. Electr. Electron. Eng., 2019.

[26] B. N. Alajmi, K. H. Ahmed, S. J. Finney, and B. W. Williams, "Fuzzy-Logic-Control Approach of a Modified HillClimbing Method for Maximum Power Point in Microgrid Standalone Photovoltaic System," IEEE Trans. Power Electron., vol. 26, no. 4, pp. 1022-1030, Apr. 2011.

[27] H. M. Hasanien and M. Matar, "A Fuzzy Logic Controller for Autonomous Operation of a Voltage Source Converter-Based Distributed Generation System," IEEE Trans. Smart Grid, vol. 6, no. 1, pp. 158-165, Jan. 2015.

[28] A. M. Farayola, A. N. Hasan, and A. Ali, "Comparison of modified Incremental Conductance and Fuzzy Logic MPPT algorithm using modified CUK converter," in 2017 8th International Renewable Energy Congress (IREC), Mar. 2017, pp. 1-6.

[29] D. Arcos-Aviles, J. Pascual, L. Marroyo, P. Sanchis, and F. Guinjoan, "Fuzzy Logic-Based Energy Management System Design for Residential Grid-Connected Microgrids,” IEEE Trans. Smart Grid, vol. 9, no. 2, pp. 530-543, Mar. 2018.

[30] M. M. S. Khan, M. O. Faruque, and A. Newaz, "Fuzzy Logic Based Energy Storage Management System for MVDC Power System of All Electric Ship,” IEEE Trans. Energy Convers., vol. 32, no. 2, pp. 798-809, Jun. 2017.

[31] H. Bevrani, F. Habibi, P. Babahajyani, M. Watanabe, and Y. Mitani, "Intelligent Frequency Control in an AC Microgrid: Online PSO-Based Fuzzy Tuning Approach," IEEE Trans. Smart Grid, vol. 3, no. 4, pp. 1935-1944, Dec. 2012.

[32] R. Syahputra and I. Soesanti, "Power System Stabilizer model based on Fuzzy-PSO for improving power system stability," in 2015 International Conference on Advanced Mechatronics, Intelligent Manufacture, and Industrial Automation (ICAMIMIA), Oct. 2015, pp. 121-126.

[33] P. Verma, R. Garg, and P. Mahajan, "Asymmetrical interval type-2 fuzzy logic control based MPPT tuning for PV system under partial shading condition," ISA Trans., vol. 100, pp. 251-263, May 2020.

[34] T. Arun Srinivas, G. Themozhi, and S. Nagarajan, "Current mode controlled fuzzy logic based inter leaved cuk converter SVM inverter fed induction motor drive system," Microprocess. Microsyst., vol. 74, p. 103002, Apr. 2020.

[35] R. Heydari, M. Gheisarnejad, M. H. Khooban, T. Dragicevic, and F. Blaabjerg, "Robust and Fast Voltage-SourceConverter (VSC) Control for Naval Shipboard Microgrids," IEEE Trans. Power Electron., vol. 34, no. 9, pp. 82998303, Sep. 2019.

[36] "Fuzzy set," Wikipedia. Jul. 09, 2020, Accessed: Jul. 16, 2020. [Online]. Available: https://en.wikipedia.org/w/index.php?title=Fuzzy_set\&oldid=966800625.

[37] H.-J. Zimmermann, Fuzzy set theory—and its applications. Springer Science \& Business Media, 2011. 


\section{BIOGRAPHY OF AUTHOR}

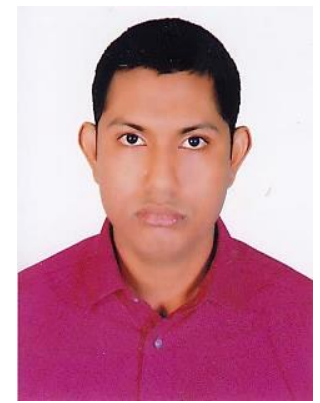

Md. Shamsul Arifin received B.Sc. in Electrical and Electronic Engineering from Bangladesh University of Engineering and Technology, Dhaka, Bangladesh in 2013, M.Sc. from Energy and Power Group in Electrical and Electronic Engineering from Bangladesh University of Engineering and Technology, Dhaka, Bangladesh in 2016, respectively. He also worked as a Graduate Research Assistant in Memorial University of Newfoundland, Canada from 2019 to 2020. He is currently working as an Assistant Professor, in the department of Electrical and Electronic Engineering, Chittagong University of Engineering and Technology, Chittagong, Bangladesh. He has published 14 research papers in refereed journals and conference proceedings. His research interests are in the field of the power system and power electronics. 